\title{
A reinfosfera na pandemia do novo coronavírus: infodemia, fake news e sociabilidade perversa
}

\author{
The reinfosphere in the pandemic of the new coronavirus: \\ Infodemia, fake news and perverse sociability
}

\begin{abstract}
Renata Rezende Ribeiro a,*
José Antonio Martinuzzo b (D)

RESUMO: O artigo integra investigações ampliadas sobre os usos das redes sociais digitais no cotidiano. Neste texto, problematizamos a produção de fake news no contexto da pandemia da Covid-19 no Brasil, a partir da prática da "reinformação em rede". O objetivo principal é buscar compreender o desenvolvimento das notícias falsas na dinâmica das relações das redes sociais digitais no Brasil, em um circuito complexo que atua na fabulação de uma "reinfosfera". Além do percurso bibliográfico, a metodologia da pesquisa consistiu na análise de conteúdo de onze fake news sobre a pandemia, que circularam no ano de 2020. O estudo revelou que a experiência da "infodemia", particularmente no contexto da reinformação, pode ser, de alguma forma, compreendida pela perversão como marca essencial da sociabilidade contemporânea, aquela que subverte e/ou rompe com a verdade factual como laço social.
\end{abstract}

Palavras-chave:Redes Sociais Digitais; Fake News; Pandemia; Reinfosfera; Perversão.

ABSTRACT: The article integrates expanded investigations on the uses of digital social networks in everyday life. In this text, we problematize the production of fake news in the context of the Covid-19 pandemic in Brazil, based on the practice of "network reinformation". The main objective is to seek to understand the development of false news in the dynamics of the relations of digital social networks in Brazil, in a complex circuit that acts in the fabrication of a "reinfosphere". In addition to the bibliographic path, the research methodology consisted of the content analysis of eleven fake news about the pandemic, which circulated in the year 2020. The study revealed that the experience of "infodemia", particularly in the context of reinformation, may be, somehow, understood by perversion as an essential mark of contemporary sociability, that which subverts and / or breaks with factual truth as a social bond. Keywords:Digital Social Networks; Fake News; Pandemic; Reinfosphere; Perversion.

\footnotetext{
a Programa de Pós-Graduação em Mídia e Cotidiano, Universidade Federal Fluminense, Niterói, RJ, Brasil.

b Departamento de Comunicação Social, Universidade Federal do Espírito Santo, Vitória, ES, Brasil.

* Correspondência para/Correspondence to: Renata Rezende Ribeiro. Endereço: Campus da UFF Gragoatá, Bloco A. Rua Alexandre Moura, n 8 - São Domingos, CEP 24.210-20, Niterói, RJ, Brasil. E-mail: renatarezende@id.uff.br.
}

Recebido em/Received: 13/04/2021; Aprovado em/Approved: 04/06/2021.

Artigo publicado em acesso aberto sob licença CC BY 4.0 Internacional (a) (i) 


\section{INTRODUÇÃO}

No século XXI a vida parece estar definitivamente atravessada por telas e ambientes digitais e a pandemia da Covid-19 ${ }^{1}$ evidenciou a dimensão complexa de um mundo interconectado por imagens e tecnologias informacionais. A era das redes intensificou a produção de diferentes expressões culturais, valores, interesses, imaginações, afetos e afetações e, nesse contexto, as notícias sobre a pandemia não escaparam às fake news ${ }^{2}$.

Com o crescimento do surto da Covid-19 no Brasil e as incertezas que surgiram junto com a expansão do vírus, uma série de dúvidas abriu espaço para notícias falsas sobre o assunto. Segundo estudo 3 realizado pela Avaaz, nove em cada dez brasileiros receberam, pelo menos, uma informação falsa sobre a Covid-19, e sete em cada dez brasileiros acreditaram em, ao menos, um conteúdo baseado em desinformação sobre a pandemia.

Além do Brasil, a pesquisa foi realizada na Itália e nos Estados Unidos, países com altos índices de infectados e mortos pela doença. O número se torna ainda mais impressionante no que se refere à crença nessas fake news: segundo o mesmo levantamento, $73 \%$ dos brasileiros entrevistados acreditaram em algum conteúdo com informações falsas sobre a pandemia.

O estudo da Avaaz trabalhou com o conceito mais usual de desinformação, definindoo como "informação verificável como falsa ou enganosa que tem potencial de causar dano ao público, como enfraquecer a democracia ou prejudicar a saúde pública". Neste texto, nossa proposta é problematizar a produção das fake news para além do conceito de desinformação, identificando, também, como uma prática de "reinformação".

Reinvidicado pelo político francês Henry de Lesquen, cujo Partido Nacional Liberal é de extrema-direita, o termo "reinformação" se baseia no princípio de que a mídia de massa tradicional não noticiaria a realidade (MANSOUR, 2019) e, por essa justificativa, desenvolveria novas versões dos fatos.

Nesse arranjo, "reinformar assemelha-se mais à rejeição de notícias da mídia tradicional - a fim de propagar teorias da conspiração -, do que oferecer uma nova oferta de informações" (MANSOUR, 2019, p. 2, tradução nossa). A pesquisadora Léda Mansour desenvolveu uma problematização a partir das orientações lexicais, levando

\footnotetext{
${ }^{1}$ A pandemia do novo coronavírus (SARS-CoV-2), agente da Covid-19, teve seus primeiros casos registrados no Brasil no final de fevereiro de 2020. Segundo dados do Ministério da Saúde, na estatística de "casos acumulados de Covid-19 por data de notificação", em 29 de fevereiro de 2020, havia dois registros, número que chegou a 10.587.001, em 01 de março de 2021. Os "óbitos de Covid-19 por data de notificação" começaram a ser marcados pelo Ministério em 17 de março de 2020 e chegaram a 465,199, em 01 de junho de 2021. Cf.: https://covid.saude.gov.br. Acesso em: 01 de junho 2021.

${ }^{2}$ Nesse texto, usamos o termo fake news a partir de sua tradução literal do inglês "notícias falsas". Temos ciência de que no universo do fact-checking, o uso do termo divide opiniões, na medida em que se é notícia, não poderia ser falsa. Imitando o texto jornalístico, para lhe roubar a credibilidade narrativa (TRAQUINA, 1999; ZELIZER, 1992), as fake news dinamizam a era da pós-verdade, definida pelo Oxford Dictionaries como "circunstâncias em que os fatos objetivos são menos influentes em formar a opinião pública do que os apelos à emoção e à crença pessoal” (D'ANCONA, 2018, p. 20). Detalhamos mais sobre a definição de fake news ao longo do texto.
}

3 Disponível em: "O Brasil está sofrendo uma infodemia de Covid-19".

https://secure.avaaz.org/campaign/po/brasil_infodemia_coronavirus/. Acesso em: 01 jun 2020. 
em conta a dicotomia verdade e mentira, e concluiu que, apesar do prefixo "re" comportar uma necessidade de ruptura (como recomeçar, refazer, restaurar, renovar, repetir), a ideia é tomada, na maior parte das vezes, pela imposição de determinada crença e isso se potencializa pela forma como "fragmentos de verdade" são hibridizados aos conteúdos falsos.

De acordo com Mansour (2019), os sites que usam a premissa da reinformação não são homogêneos e na contemporaneidade se tornaram uma reinfosfera: "uma comunidade de reinformação conservadora". A autora situa a estratégia da "reinformação" dentro do universo das notícias falsas, mas insiste sobre a importância da postura dos indivíduos que aderem a tais discursos e desconsideram a verdade, a preexistência e o contexto de fatos e acontecimentos.

Dessa forma, chegamos à outra questão nesse artigo: o porquê de a mentira e as manipulações providas pela estrutura da "reinformação" e seus conteúdos prosperarem tanto na atualidade. Aqui se investiga o fundamento da perversão ${ }^{4}$ na atual sociabilidade, como hipótese para se responder a essa problemática.

Para tanto, a metodologia de nossa investigação incluiu percurso sobre o referencial teórico de diferentes áreas do conhecimento, entre eles, a comunicação, a psicanálise, a sociologia, a filosofia, a antropologia, entre outros, e análise de conteúdo de onze (11) notícias falsas relativas à pandemia do novo coronavírus, que circularam entre os meses de março e junho de 2020 nas redes sociais digitais.

Dessa forma, nossa intenção é avançar no estudo do fenômeno vertiginoso da produção e circulação de fake news, no âmbito da "reinformação" e no contexto de uma sociabilidade perversa, que subverte e/ou rompe com a verdade, estabelecendo a "mentira midiatizada" como um laço social.

\section{INFODEMIA E REINFORMAÇÃO}

Antes mesmo de passarmos à consideração dos temas desta seção, avaliamos ser pertinente aludir ao tipo de sociabilidade que dá lugar aos fenômenos como os batizados de "infodemia" e "reinformação". Trata-se de uma sociedade midiatizada, que experimenta uma dinamização inaudita na sua economia da atenção e dos afetos. Experimentamos o que se denomina de sociedade midiatizada (SODRÉ, 2002), um tipo peculiar de civilização mobilizada por conteúdos midiáticos articulados em torno de redes comunicacionais viabilizadas por uma colossal teia formada por tecnologias digitais de comunicação (TICs) e meios tradicionais de difusão, estes também alcançados pela influência da virtualidade.

Nesse ambiente, a digitalidade, ou a experiência do digital, se incrementa alucinadamente. E a pandemia do novo coronavírus só fez multiplicar a pandemia da informacionalização, em expansão há cerca de cinco décadas, e que atinge uma densidade jamais vista no tocante à circulação de informação, com críticos efeitos no modo de viver este tempo. Segundo dados da Kantar Ibope Media, Facebook, Instagram e WhatsApp cresceram 40\% ainda no início da pandemia 5 .

\footnotetext{
4 Em sentido stricto, a partir do campo psicanalítico, como objetivamos demonstrar ao longo do texto.

5 Disponível em: https://exame.com/tecnologia/como-valvula-de-escape-na-quarentena-redes-sociais-crescem-nomundo/. Acesso em: 03 mar 2021.
} 
Nos anos 1970, o Nobel de Física Herbert Simon já antevia a questão econômica fundamental do século XXI: "O que a informação consome é bastante óbvio, consome a atenção dos seus destinatários. Assim, uma riqueza de informação cria uma pobreza de atenção" (MARTINUZZO, 2014, p. 20). Nesse cenário, turbinado inclusive pela pandemia, o que experimentamos é a vertigem dessa dinâmica, seja porque cada vez mais as relações e as interfaces migram para os laços digitais, reduzindo-se a meras trocas informacionais, seja porque toda a vida vira informação coletável e processável, distribuída em redes comunicacionais atualizadas sem parar.

Esse novo modus vivendi tornou-se um lucrativo negócio capitalístico nas mãos das empresas mais valiosas do planeta, denominadas "big techs" (Amazon, Apple, Google, Facebook e Microsoft). É nesse contexto de vida midiatizada e de alucinação informacional, em que a disputa pela atenção e pelos afetos, mobilizados por razões de guerras mercadológicas até embates por hegemonia política, requerem renovadas estratégias de captura e manutenção do olhar e da cognição dos indivíduos que conformam públicos-alvo específicos.

Discutido o contexto ampliado, para melhor entender o significado do neologismo "infodemia", utilizado inclusive pela Organização das Nações Unidas (ONU) e pela Organização Mundial da Saúde (OMS) ${ }^{6}$, no tocante à pandemia do novo coronavírus, vale dissecar o substantivo recém-constituído, formado pelos nomes "informação" e "pandemia". Considerando o escopo desta abordagem, informação é, segundo Neiva (2013, p. 294), tanto o "ato ou efeito de informar" quanto a "comunicação ou recepção de um conhecimento ou juízo". E ainda: "conjunto de conhecimentos reunidos sobre determinado assunto". Já pandemia é, de acordo com o Houaiss (2009, p. 1.421), "enfermidade epidêmica amplamente disseminada", cuja etimologia se refere a "povo inteiro".

Em linhas gerais, pode-se concluir que "infodemia" tende mesmo a conceituar um fenômeno social de vertigem informacional constituída de narrativas diversas acerca de fatos verdadeiros e falsos, textos com informações precisas e imprecisas sobre eventos da vida real, registrada forma de pervasiva, com veloz disseminação e alta capacidade de emissão/atualização. Para a OMS, infodemia é a "quantidade excessiva de informações sobre um problema, o que dificulta a identificação de uma solução", podendo "espalhar informação falsa, desinformação e rumores durante uma emergência de saúde". "Infodemias podem dificultar uma resposta eficaz de saúde pública e criar confusão e desconfiança entre as pessoas”, avalia a Organização Mundial de Saúde.

No caso específico da Covid-19, "infodemia" pode ser considerada como uma "enfermidade" informacional, posto que constituída de conteúdo de desinformação e mentira, que alcança um número gigantesco de receptores os quais, possuindo meios de comunicação pessoal de massa, ou redes sociais digitais, procedem à sua replicação naquilo que se pode determinar "reinformação", ou seja, reproduzindo formas ou padrões das mídias tradicionais em uma confusão enunciativa e interpretativa (RIBEIRO, 2020). Em muitos conteúdos há uma espécie de aparência da verdade, como vamos demonstrar na análise a seguir, que permitem uma interpretação diferente de determinado acontecimento ou fato.

${ }^{6}$ Disponível em: https://www.un.org/en/un-coronavirus-communications-team/un-tackling-'infodemic'-misinformationand-cybercrime-covid-19. Acesso 03 mar 2021. 
De acordo com Divina Frau-Meigs (2019), a influência e a persuasão são mecanismos antigos usados para fabricação de notícias falsas, rumores e teorias do complô, mas a autora destaca que o ambiente digital facilitou a transformação do próprio dado, principalmente as redes sociais na Internet.

\section{FAKE NEWS, PANDEMIA E “REINFORMAÇÃO”}

A definição de fake news tem sido constantemente problematizada por diferentes autores a partir de variadas perspectivas. Conforme situamos, a propagação de informações baseadas em mentiras e boatos não é novidade, mas o que marca o cenário contemporâneo, particularmente, é a produção de notícias falsas no contexto da midiatização, principalmente a efervescência das redes sociais. O cenário da web 2.o fez do território digital lugar propício para desinformação, na medida em que "mais do que o papel de criador, pode-se atribuir à internet a força potenciadora de adulterar, reaproveitar e espalhar as mensagens a uma escala sem precedentes" (SILVA, 2019, p. 7).

Para D’ancona (2018, p. 34), o aumento de informações inverídicas está relacionado à época em que vivemos, onde "a indignação dá lugar à indiferença e, por fim, à conivência. A mentira é considerada regra, e não exceção". O autor afirma que na era da chamada 'pós-verdade', as versões do público sobre os fatos predominam em relação à própria verdade, mesmo quando essa é atestada.

Edson Tandoc, Zheng Wei Lim e Richard Ling (2018, p. 139, tradução nossa) afirmam que as mídias sociais não mudaram apenas a distribuição de notícias, mas desafiaram, inclusive, as crenças tradicionais de como as notícias devem ser. Segundo os autores, redes sociais como Twitter e Facebook facilitaram a disseminação de informações falsas, na medida em que os usuários navegam por infinitas camadas compartilhadas por várias fontes diferentes e costumam acreditar nas fontes socialmente mais próximas para legitimar a veracidade dos dados que acreditam. No entanto, segundo eles, os usuários raramente verificam tais informações antes de compartilharem.

Nesse contexto, as fake news desenvolvem sentidos complexos ao universo da comunicação e da mídia, pois atravessam as estruturas da verdade e da mentira, do real e da ficção, do atual e do virtual, em uma correlação intrínseca à questão da ética e da moral7. Para Divina Frau-Meigs (2019), na atual sociedade da informação há um modelo confuso nos quais as vidas pública e privada se tornaram híbridas, e essa mistura desenvolveu um território fértil para o desenvolvimento de informações falsas.

Para Frau-Meigs (2019), esse cenário é também consequência das atuais mídias sociais, principalmente dos sites de redes digitais como Facebook e Twitter, que privilegiam os comentários e as formas narrativas mais curtas e superficiais, como as postagens, em detrimento de formas narrativas longas, com argumentação mais articulada, na medida em que a verificação dos fatos não é a prioridade dos usuários dessas redes de

\footnotetext{
${ }^{7} \mathrm{~A}$ partir de Aristóteles (2009), sinteticamente, ética como conjunto de regras de conduta aplicadas às sociedades, mas sob a perspectiva individual. Moral enquanto conjunto de regras de conduta em determinada cultura em um sistema social.
} 
informação.

Ao analisar as ambiências da 'pós-verdade' nos Estados Unidos, Michiko Kakutani (2018, p.25) lembra do conceito de contranarrativa que, segundo o historiador Richard Hofstadter descreve como um "estilo paranoide", no qual há "uma visão alimentada por fervorosos exageros, desconfiança e fantasia conspiratória". A autora também remarca o declínio da importância do discurso racional relacionado à democratização libertadora da informação na Internet que, para além da inovação, também deu origem a uma "enxurrada de desinformação e relativismo", como é possível evidenciar pela "atual epidemia de notícias falsas" (2018, p.55).

Já para Morozov (2018, p.184), “o problema não são as fake news, mas a velocidade e a facilidade de sua disseminação". O autor nos lembra que os dados (informações) representam o petróleo do século XXI e, sob a ótica das plataformas digitais, as fakes news são as notícias mais lucrativas. Segundo ele, isso acontece porque o próprio sistema capitalista, marcado pela estrutura digital, torna rentável produzir e compartilhar esse tipo de notícias para atrair mais audiência, por meio de curtidas, comentários e compartilhamentos.

De acordo com Matos e Ripoll (2017, p.6), o consumo e a disseminação da desinformação podem ser considerados como uma "epidemia zumbi" - figura folclórica da cultura pop mundial, que representa "uma alma que vaga em um corpo destroçado”. A 'zumbificação da informação' refere-se ao processo de disseminação e consumo de informação falsa ou distorcida, sem percepção ou conhecimento, devido à ausência de interpretação crítica e checagem de fontes". Os autores também marcam que o cenário das fake news está relacionado às características técnicas e culturais da sociedade da informação, principalmente com o surgimento das redes sociais, na geração web 2.0.

Conforme já situamos, a produção de notícias falsas não é novidade, mas com o efeito da digitalização da vida, principalmente com o desenvolvimento dos sites de redes sociais, isso foi renovado. Segundo Frau-Meigs (2019), a partir de 2008, com o aprimoramento da web 2.0, a ampliação da participação e colaboração dos usuários no cotidiano e o aumento dos dados massivos em rede, houve uma virada cognitiva, voltada à criação de engajamentos e emoções para suscitar mais a circulação das interpretações e das crenças do que os dados baseados na realidade em si.

Frau-Meigs afirma, ainda, que os governos populistas se beneficiaram da lógica da "reinformação", na medida em que passaram a utilizar ora os conteúdos, ora os formatos narrativos das mídias de massa para criar confusões entre fatos e interpretações, promovendo uma produção frenética de falsas informações.

\section{REINFOSFERA DA PANDEMIA}

No Brasil, há diversos exemplos de fake news que podem ser analisadas a partir da noção de "reinformação". Em nossa pesquisa, investigamos onze (11) notícias falsas sobre o coronavírus, que circularam nas redes digitais brasileiras. Durante a coleta, foi possível observar que muitas informações se baseavam em dúvidas genuínas da população e eram pautadas em uma possível esperança de que a pandemia não fosse tão grave ou que pudesse ser facilmente resolvida. 
Para desenvolver a investigação empírica, optamos pela análise de conteúdo, método que se desenvolve em um conjunto de técnicas cujos procedimentos se constituem em sistematizações e descrições dos dados coletados. Nesse sentido, a composição se dá pela organização da análise, pela codificação dos resultados, pelas categorizações ou tipificações do conteúdo selecionado, pelas inferências e pela informatização da análise. Para Bardin (2009, p.21), a análise de conteúdo é organizada em três principais estruturas: pré-análise, exploração do material e tratamento dos resultados.

Situada em uma perspectiva exploratória e qualitativa, a metodologia teve início com o recorte da temática (fake news e pandemia), a coleta do material e a posterior seleção de conteúdo para o desenvolvimento dos quadros de análise. É importante evidenciarmos o contexto inerente ao período de produção da coleta dos dados, diretamente influenciado pela pauta do momento e pelos assuntos que ocupam o cotidiano mundial (a pandemia). De acordo com Bardin (2009), a análise de conteúdo tem como função o "desvendar crítico", no qual podem ser interpretadas:

Mensagens obscuras que exigem uma interpretação, mensagens com um duplo sentido cuja significação profunda só pode surgir depois de uma observação cuidadosa ou de uma intuição carismática. Por detrás do discurso aparente, geralmente simbólico e polissêmico, esconde-se um sentido que convém desvendar (BARDIN, 2009, p.37).

Desta forma, ao utilizar esse tipo de análise, buscamos evidenciar o que não está aparente à primeira vista, ou seja, tentar verificar como se desenvolve tais mensagens (fake news) em uma perspectiva qualitativa.

Conforme verificamos nos quadros 1 e 2, a maior parte das notícias falsas estão relacionadas a tratamentos, curas milagrosas ou possíveis prevenções ao vírus. $\mathrm{Na}$ análise foi possível ainda identificar outras duas temáticas de informações falsas que se espalharam pelas redes sociais: notícias que atrelavam o surto de covid-19 a razões e causas de cunho político e informações que tentavam amenizar a gravidade da pandemia.

Das onze (11) fakes news analisadas, sete delas continham pelo menos uma informação verdadeira misturada a conteúdos fictícios e/ou descontextualizados, conforme podemos verificar no quadro 1. Entre as notícias de cunho político, destacamos o texto que afirmava que o vírus Sars-Cov-2 seria uma arma biológica criada pelo governo

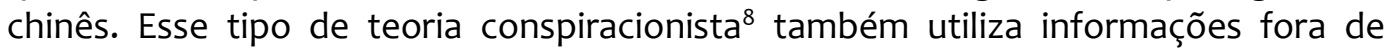
contexto. Nesse caso, o único dado apurado e confirmado foi a citação da China como país que declarou, oficialmente, o primeiro caso da doença. No entanto, não houve qualquer prova de que o vírus tenha sido produzido em laboratório, nem que tenha sido espalhado de forma intencional.

A outra notícia falsa (n.2) afirmava que os caixões mostrados em reportagens do estado do Amazonas estariam vazios. As imagens dos caixões eram reais, mas de outra data, ocasião e localidade, não tendo qualquer relação com a pandemia da Covid-19.

${ }^{8} \mathrm{O}$ dicionário Oxford define conspiração ou conspiracionismo como "a teoria de que um evento ou fenômeno ocorre como resultado de uma conspiração entre as partes interessadas [...] uma crença de que algum agente ou instituição secreta e influente é motivada por questões políticas, sendo responsável por um evento inexplicável". 
Quadro 1. Relação das notícias falsas com partes de conteúdos verificados (verdadeiros).

\begin{tabular}{|c|c|c|c|c|}
\hline N. & NOTÍCIA FALSA & TEMA & $\begin{array}{l}\text { CONTEÚDO NÃO } \\
\text { COMPROVADO }\end{array}$ & $\begin{array}{c}\text { CONTEÚDO VERIFICADO } \\
\text { (APURADO) }\end{array}$ \\
\hline 1. & $\begin{array}{l}\text { "O novo coronavírus foi } \\
\text { desenvolvido em laboratório } \\
\text { por cientistas chineses que } \\
\text { pretendiam usar o vírus como } \\
\text { uma arma biológica" }\end{array}$ & $\begin{array}{l}\text { Teoria da conspiração } \\
\text { de que a China } \\
\text { produziu o vírus da } \\
\text { Covid-19 para expandir } \\
\text { o comunismo pelo } \\
\text { mundo; }\end{array}$ & $\begin{array}{l}\text { Não há qualquer } \\
\text { comprovação de que o vírus } \\
\text { tenha sido produzido em } \\
\text { laboratório e muito menos } \\
\text { que tenha sido espalhado de } \\
\text { forma intencional pela China. }\end{array}$ & $\begin{array}{l}\text { O primeiro caso oficial } \\
\text { detectado da Covid-19 foi } \\
\text { em Wuhan, na China. }\end{array}$ \\
\hline 2. & 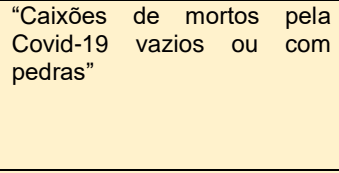 & $\begin{array}{l}\text { Série de publicações } \\
\text { sobre caixões vazios ou } \\
\text { com pedras, para } \\
\text { minimizar ou contestar } \\
\text { o número de mortes por } \\
\text { Covid-19. }\end{array}$ & 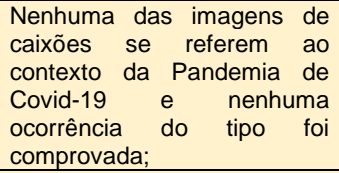 & $\begin{array}{l}\text { As imagens dos caixões } \\
\text { são reais, mas são de } \\
\text { outras datas e outras } \\
\text { ocasiões, localidades, não } \\
\text { tendo qualquer relação com } \\
\text { a pandemia da Covid-19. }\end{array}$ \\
\hline 3. & $\begin{array}{l}\text { "Pacientes curados da Covid- } \\
19 \text { com hidroxicloroquina" }\end{array}$ & $\begin{array}{lr}\text { "Quatro } & \text { pacientes } \\
\text { curados em SP } & \text { com } \\
\text { uso } & \text { da } \\
\text { hidroxicloroquina" } & \end{array}$ & $\begin{array}{l}\text { O paciente da notícia não } \\
\text { teve coronavírus, e o hospital } \\
\text { fotografado não é de São } \\
\text { Paulo, mas de Porto Alegre. } \\
\text { O paciente citado se } \\
\text { recuperava de um enfisema } \\
\text { pulmonar. Além disso, não há } \\
\text { nenhuma informação oficial } \\
\text { que confirme que há curados } \\
\text { da Covid-19 por uso da } \\
\text { cloroquina }\end{array}$ & $\begin{array}{l}\text { A fotografia utilizada na } \\
\text { imagem é verdadeira e } \\
\text { ilustra um paciente que } \\
\text { esteve internado, } \\
\text { acompanhado da filha. }\end{array}$ \\
\hline 4. & $\begin{array}{l}\text { "Ingerir desinfetante pode } \\
\text { combater o coronavírus" }\end{array}$ & $\begin{array}{lrr}\text { "Eu vi } & \text { que } & \text { o } \\
\text { desinfetante } & \text { dá } & \text { um } \\
\text { nocaute } & & \text { (no } \\
\text { coronavírus) em } & \text { um } \\
\text { minuto. Um minuto". }\end{array}$ & 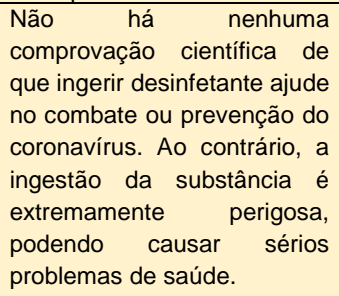 & $\begin{array}{l}\text { O desinfetante ajuda no } \\
\text { combate ao vírus, mas não } \\
\text { para ingestão; apenas para } \\
\text { limpar objetos e ambientes. }\end{array}$ \\
\hline 5. & $\begin{array}{l}\text { "Tratamentos para combater } \\
\text { o coronavírus" }\end{array}$ & $\begin{array}{l}\text { Demonstração de } \\
\text { produtos naturais com a } \\
\text { promessa de curar o } \\
\text { vírus. }\end{array}$ & $\begin{array}{l}\text { Nenhum dos tratamentos } \\
\text { naturais que o médico aponta } \\
\text { como eficaz tem } \\
\text { comprovação científica. }\end{array}$ & $\begin{array}{l}\text { Os produtos citados } \\
\text { existem e são associados a } \\
\text { outras curas naturais, não } \\
\text { tendo qualquer relação com } \\
\text { a Covid. }\end{array}$ \\
\hline 6. & $\begin{array}{l}\text { "Ex-farmaceutico afirma que } \\
\text { criou uma substância capaz } \\
\text { de curar o coronavírus" }\end{array}$ & $\begin{array}{l}\text { Chamada Parow Off } \\
\text { Coron, o ex- } \\
\text { farmacêutico chegou a } \\
\text { vender o produto, que } \\
\text { ele produzia enviando a } \\
\text { receita a um laboratório } \\
\text { de manipulação. }\end{array}$ & 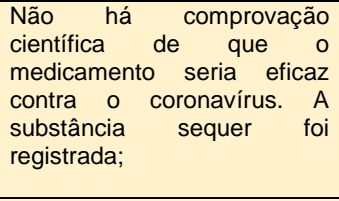 & $\begin{array}{l}\text { O produto ParowOff } \\
\text { existia } \\
\text { realmente). }\end{array}$ \\
\hline 7. & $\begin{array}{l}\text { "Médica do interior de São } \\
\text { Paulo associa soro da } \\
\text { imunidade como solução para } \\
\text { o novo coronavírus" }\end{array}$ & $\begin{array}{l}\text { Soro como solução } \\
\text { para aumentar a } \\
\text { imunidade e combater o } \\
\text { coronavirus. }\end{array}$ & $\begin{array}{l}\text { Não há nenhuma evidência } \\
\text { científica de que a infusão de } \\
\text { soros, com qualquer dose de } \\
\text { vitaminas, minerais, } \\
\text { aminoácidos, antioxidantes } \\
\text { ou outros nutrientes, tenha } \\
\text { efeito preventivo contra o } \\
\text { novo coronavírus. }\end{array}$ & $\begin{array}{l}\text { A médica vendia um soro e } \\
\text { as imagens mostravam } \\
\text { pacientes "reais", utilizando } \\
\text { o tratamento indicado por } \\
\text { ela. }\end{array}$ \\
\hline
\end{tabular}

Fonte: autoria própria.

Tais exemplos evidenciam o investimento retórico com a intenção principal de persuadir e manipular pessoas, marca constitutiva da perversão. Esses fatos "reinformados", quando deslocados de seus contextos específicos, contribuem para autorizar discursos de intolerância e sectarismo. Nesse sentido, a infodemia no contexto de uma sociabilidade perversa, dinamizada pela prática da reinformação, é uma via que corrói insidiosamente a existência civilizada, promovendo uma ruína diuturna da verdade factual como laço social. Sob a farra das fake news e a permissividade das redes, testemunhamos a subversão/negação da realidade objetiva e a consolidação de um tempo de perversão epidêmico.

Voltando aos dados encontrados na pesquisa, entre as falsas promessas de cura contra a doença, identificamos cinco notícias com conteúdos apurados misturados à invenções (números 3, 4, 5, 6 e 7 do Quadro 1). Três delas, inclusive, se apoiam sobre 
figuras de autoridade ${ }^{9}$ da área da saúde.

Em vídeo ${ }^{10}$, um médico de Tocantins aponta uma série de soluções e supostas curas, utilizando produtos naturais para combater o coronavírus. Outra médica faz propaganda para o que chama de "soro da imunidade" e filma os próprios pacientes adotando um método de proteção sem nenhuma comprovação científica. Há também um farmacêutico de Minas Gerais, que possuía o registro de profissão cassado, mas que vendia um antídoto que ele afirmava ser a cura contra a covid-19.

Todos esses exemplos podem ser compreendidos pela prática da reinformação, na medida em que utilizam elementos factuais em uma reinterpretação, misturando dados de forma a confundir o público. Os difusores, quando questionados, apelam para a noção de "fatos alternativos"

As outras quatro fake news analisadas (Quadro 2) se referiam a conteúdos integralmente falsos, sem qualquer indício ou fragmento factual e sem qualquer localização de autoria, sendo disseminadas nas redes sociais digitais.

Diante desse quadro, podemos situar a formação de uma reinfosfera sobre a pandemia. Mas para além de diagnosticar as estratégias da "reinformação" dentro do universo da disseminação dos conteúdos falsos, nos questionamos, também, sobre a ambiência que revela esse cenário.

A experiência contemporânea da "infodemia", no contexto da "reinformação" e suas reluzentes fake news, pode ser de alguma forma explicada pela perversão como marca essencial da sociabilidade que se constitui neste princípio de milênio, a qual toma a mentira como laço social.

\footnotetext{
${ }^{9} \mathrm{Na}$ pesquisa, houve coleta de dados de forma mais abrangente, incluindo o mapeamento dos principais difusores dessas informações falsas. No entanto, em virtude do recorte, esse item não foi detalhado.

10 "Golpistas se aproveitam do medo da população em meio à pandemia de coronavírus". Ver mais in: https://g1.globo.com/fantastico/noticia/2020/03/22/golpistas-se-aproveitam-do-medo-da-populacao-em-meio-apandemia-de-coronavirus.ghtmlAcesso em: 30/03/2021.

${ }^{11}$ A defesa de "fatos alternativos" começou a circular, com mais evidência em 2016, quando a conselheira do então presidente dos Estados Unidos, Donald Trump, Kellyanne Conway, em uma entrevista para TV, refutou dados, dizendo que o governo americano trabalhava com "fatos alternativos". Ver mais in: https://www.nexojornal.com.br/interativo/2017/03/31/Voc\%C3\%AA-sabe-o-que-\%C3\%Ag-verdade-e-o-que-\%C3\%Ag\%E2\%80\%98fato-alternativ0\%E2\%80\%99. Acesso em 30/08/2019.
} 
Quadro 2. Relação das fake news com total conteúdo falso.

\begin{tabular}{|c|c|c|c|c|}
\hline N. & NOTÍCIA FALSA & TEMA & $\begin{array}{l}\text { CONTEÚDO NÃO } \\
\text { COMPROVADO }\end{array}$ & $\begin{array}{c}\text { CONTEÚDO VERIFICADO } \\
\text { (APURADO) }\end{array}$ \\
\hline 1. & $\begin{array}{l}\text { "Fazer gargarejo com água e } \\
\text { sal protege contra a Covid- } \\
19 \text { " }\end{array}$ & $\begin{array}{l}\text { Vídeo veiculado nas } \\
\text { redes sociais afirma } \\
\text { que o coronavírus, } \\
\text { antes de chegar aos } \\
\text { pulmões, fica preso na } \\
\text { garganta por quatro } \\
\text { dias. Por isso a } \\
\text { recomendação seria } \\
\text { beber muita água e } \\
\text { fazer gargarejo com } \\
\text { água morna e sal ou } \\
\text { vinagre, para evitar que } \\
\text { o vírus chegue ao } \\
\text { pulmão. }\end{array}$ & $\begin{array}{l}\text { Não há nenhum tratamento } \\
\text { específico contra o } \\
\text { coronavírus e a técnica citada } \\
\text { não é eficaz segundo } \\
\text { médicos e especialistas. }\end{array}$ & $\begin{array}{l}\text { Não foram encontradas } \\
\text { informações verdadeiras. }\end{array}$ \\
\hline 2. & $\begin{array}{l}\text { "Se você conseguir segurar a } \\
\text { respiração por } 10 \text { segundos, } \\
\text { não está com Covid-19" }\end{array}$ & $\begin{array}{l}\text { Texto sugere que as } \\
\text { pessoas segurem o ar } \\
\text { por dez segundos para } \\
\text { saber se têm fibrose } \\
\text { nos pulmões provocada } \\
\text { pelo novo coronavírus. }\end{array}$ & $\begin{array}{l}\text { A técnica citada não possui } \\
\text { nenhuma evidência médica. } \\
\text { Para saber se há fibrose ou } \\
\text { não, são necessários exames } \\
\text { específicos. }\end{array}$ & $\begin{array}{l}\text { Não foram encontradas } \\
\text { informações verdadeiras. }\end{array}$ \\
\hline 3. & $\begin{array}{l}\text { "Coronavírus fica aderido à } \\
\text { língua das pessoas por três } \\
\text { dias" }\end{array}$ & $\begin{array}{l}\text { Áudio veiculado no } \\
\text { Whatsapp, afirma que o } \\
\text { coronavírus fica aderido } \\
\text { à língua das pessoas } \\
\text { por três dias, por isso, } \\
\text { basta escovar bem a } \\
\text { língua para combater o } \\
\text { vírus. }\end{array}$ & 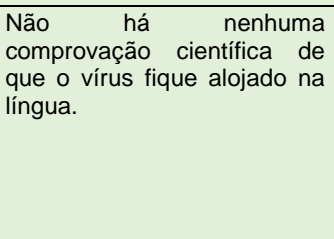 & $\begin{array}{l}\text { Não foram encontradas } \\
\text { informações verdadeiras. }\end{array}$ \\
\hline 4. & $\begin{array}{l}\text { "Ácido gástrico mata o } \\
\text { coronavírus" }\end{array}$ & $\begin{array}{l}\text { Texto divulgado no } \\
\text { Facebook afirma que } \\
\text { um jovem pesquisador } \\
\text { da China, sem nome, } \\
\text { recomenda chás } \\
\text { quentes e caldos para } \\
\text { neutralizar o vírus e } \\
\text { sugere a ingestão de } \\
\text { água a cada } 15 \text { minutos } \\
\text { porque o ácido gástrico } \\
\text { mataria o vírus. }\end{array}$ & $\begin{array}{l}\text { A técnica citada não possui } \\
\text { nenhuma } \quad \text { comprovação } \\
\text { científica. }\end{array}$ & $\begin{array}{l}\text { Não foram encontradas } \\
\text { informações verdadeiras. }\end{array}$ \\
\hline
\end{tabular}

Fonte: autoria própria.

\section{SOCIABILIDADE PERVERSA E A MENTIRA COMO LAÇO SOCIAL}

Ao narrar o espírito do tempo e seus sujeitos, a psicanálise acabou por constituir uma nomeação acerca da experiência de realidade, ela mesma construída no campo das palavras e suas significações (LAPLANCHE \& PONTALIS, 2016).

Neuróticos, perversos, psicóticos, histéricos, entre outros termos caros à psicanálise, tornaram-se significantes comuns para se configurar a narrativa da vida, em maior ou menor grau, com cores locais, nos quatros cantos do mundo, participando decisivamente da nomeação das sociabilidades contemporâneas.

Seguindo o escopo psicanalítico, registra-se nesta virada de milênio uma transição nos modos de constituição subjetiva e de formação dos laços sociais majoritários. De uma época eminentemente neurótica, chegamos a um tempo organizado pela perversão estrutural. Ou seja, de um tempo de relação atávica com os limites e as limitações da realidade objetiva e de um projeto de civilização fundado em freios e contrapesos da Lei e das leis, com seus mal-estares peculiares, passamos a uma era de negação, em vários níveis e intensidades, das contenções civilizacionais e mesmo dos fatos da realidade como limitadora de impulsos e pulsões agressivos e atinentes ao submetimento do outro a desejos e delírios disfarçados de verdade. 
Esgarçamentos das interfaces colaborativas pela prevalência do individualismo, fundamentalismos, intolerâncias, dogmatismos, e preponderância da "lei do mais forte", entre outros sintomas sociais, não são uma invenção deste tempo, mas, inegavelmente, ganharam outro status na consecução da vida contemporânea, particularmente com o desenvolvimento das redes digitais, com protagonismo inédito, constituindo, fundamentalmente, uma realidade perversa.

Segundo Dufour (2013), saímos da sociedade neurótica e entramos numa sociedade perversa. Nem todos são perversos, mas a liderança perversa instala e instiga a perversidade em rede. Isso porque, de acordo com o autor, as posições subjetivas possíveis (neurótico, perverso e psicótico) podem descrever tanto sujeitos (ser-simesmo) quanto comunidades (ser-junto).

Nessa linha, ainda que Freud (1997; 2010), tenha tratado das perversões apenas relativamente às pulsões sexuais, há décadas emprega-se o termo perverso para falar do sujeito que lida mal com os limites da realidade, não suporta frustração, interrupção ou contenção de suas pulsões de agressão, dominação e destruição, agindo sem limites civilizacionais clássicos para manter seu "apetite" por submetimentos sempre satisfeito.

O neurótico estabelece uma relação de dívida com o outro, que tudo lhe deu, e introjeta os limites (a lei, a ética, as interdições) que lhe garantiriam a existência estável diante dos riscos impostos pelo ambiente inóspito do planeta e pela agressividade estrutural dos semelhantes, seguindo a lógica de um pacto civilizatório com regras do campo simbólico e subsunção às leis da natureza.

O perverso, de outro modo, não deve nada a ninguém. "Ao contrário do neurótico, esmagado por uma dívida simbólica impossível de ser paga, coagido ao sentimento de culpa, o perverso não deve nada. Tudo Ihe é devido", esclarece Dufour (2013, p. 297). Nesse sentido, o perverso entende a lei, a regra, mas a subverte, nega ou faz as suas próprias, seguindo uma lógica de funcionamento pulsional. O autor retoma o pensamento de Lacan que, em 1967, previu o surgimento de um "novo adulto que nada mais seria que uma 'criança generalizada', em outras palavras, um perverso polimorfo prolongado” (2013, p. 352).

A caracterização de Dufour ajuda a enxergar com mais clareza a peculiaridade da sociedade contemporânea:

O que distingue o perverso do neurótico é, basicamente, a questão da relação com a lei. O neurótico é aquele que se submete à lei, por livre espontânea vontade ou à força. Satisfeito ou não (e quase sempre é 'não'), ele se submete, mesmo que se prejudique. Ao passo que o perverso, não. Ele desrespeita a lei, recusa-a. Em ambos casos, é verdade, 'existe algo, em vez de nada', mas enquanto o neurótico considera dever obedecer à lei que supostamente rege esse algo, o perverso considera que a lei é sempre a lei dos outros obedecendo ao Outro, nunca a sua lei, a única que interessa (DUFOUR, 2013, p. 302).

Há algumas marcas subjetivas do perverso que se vêm na intersubjetividade hoje. Podemos citar, a negação da realidade, dos limites (regras, lei, ética), da responsabilização, com o triunfo da indiferença e a desvalorização do outro. $O$ outro (a alteridade) não representa nada ou pouco além do que seu valor de uso, sendo descartável e totalmente substituível. Há o imperativo do gozo (pulsão) pessoal, sendo o outro objeto de satisfação própria. 
Registra-se, assim, uma excessiva manifestação de egocentrismo, revelada pelo individualismo, pela falta de compaixão e pela indiferença. Remorso, vergonha ou culpa estão minguando como ingredientes da sociabilidade hodierna, por exemplo, algo percebido com nitidez, na questão da imigração planeta afora.

A negação da realidade factual em detrimento de interesses de poder é outra marca. Tal realidade se verifica com a tendência à mentira, o investimento cognitivo e retórico sem comprometimento com a percepção da realidade e com a intenção majoritária de manipular e controlar as pessoas.

Esse quadro de perversidade estrutural pode ser visualizado nesta era da pós-verdade, e seu preposto mais reluzente, as fake news. Como esclarece D'Ancona (2018, p. 34), "as mentiras, as manipulações e as falsidades políticas enfaticamente não são o mesmo que a pós-verdade". As fake news são mentiras, falsidades e manipulações tornadas laços sociais, porque ungidas com a indiferença ou mesmo a conivência de interlocutores, muitas vezes em escala ampliada, como nas redes sociais digitais e nos aplicativos de mensagem pessoal/grupal.

A explicação de Dufour (2013) contribui para entender o quadro contemporâneo, incluindo o fulgurante fenômeno da pós-verdade. Segundo este pensador, já ultrapassamos a perversidade de primeira ordem, que reconhecia a verdade, o limite, a lei, ainda que os subvertesse (a perversão no tempo da verdade). Hoje há, também, o crescimento assustador da perversidade de segunda ordem, aquela que rompe com a verdade, o limite, a lei, constituindo o império da pós-verdade, do sem-limite, da implosão dos laços sociais lastreados pelos ideais de fraternidade, igualdade, lealdade, viabilizados, entre outros, pelo reconhecimento dos fatos em comum, sejam estes eventos ou narrativas sobre eventos.

Vivemos um tempo eminentemente perverso. A falta de limite caracteriza esta era, marcada pela descrença nas instituições e valores civilizatórios, dando lugar a depressões, inapetências, tiranias atomizadas e paranóias. Não importa a realidade, mas a sensação, o gozo. No caso das fake news, um duplo gozo perverso: o de divulgação, circulação e reverberação de uma versão particular falseada sobre fatos e agendas, com potencial alcance global, e o de conquista de atribuição de valor de verdade a versões pseudojornalísticas dos fatos, cativando audiências e seguidores. Ou seja, como no atual contexto socioténico, uma fake news pode ser substituída por outra sucessivamente, cria-se uma cadeia desses gozos perversos: o de difundir midiaticamente uma mentira e ainda o de chancelá-la como "verdade" desajustada da realidade junto a imensos contingentes.

Nesse contexto de objetificação do outro, a mentira vale por sua função, independentemente do seu significado ético-moral. Estamos no tempo de reificação de tudo, inclusive das pessoas, que valem por seu uso, por sua condição utilitária, e não pelo que são como semelhantes. A recusa da lei, do limite, que permanecem submetidos à ordem do gozo ininterrupto e a coisificação pervasiva, sem as amarras ético-morais, são marcas da perversão endêmica, habitat da 'pós-verdade'.

A verdade factual é dura, impõe aos delírios e desejos sádicos/agressivos o limite do fato. A mentira é flexível, dócil, maleável, moldável aos desejos mais recônditos/inconfessáveis da perversidade, sendo capaz de confirmar expectativas e sustentar vontades, das mais simplórias às tirânicas. A verdade pode ser amarga, a mentira, quase sempre é doce ao paladar do perverso, como sujeito e como comunidade. Ao subverter a lógica da verdade dos fatos à vontade de "verdade" 
lastreada por diversos interesses particulares e subjetivos, as notícias falsas são sintomáticas de uma sociabilidade atravessada pela perversão, uma estrutura (subjetiva e social) que se caracteriza por apresentar dificuldades em lidar com os limites da realidade, insistindo em corrompê-los.

Para Freud (2010, p. 121), "os juízos de valor dos homens são inevitavelmente governados por seus desejos de satisfação e, portanto, são uma tentativa de escorar suas ilusões com argumentos". O perverso faz isso sem culpa ou responsabilização. A sociedade perversa segue esse caminho numa marcha de insensatez rumo às tiranias pervasivas, à ruína da democracia liberal e o desbotamento dos valores iluministas.

Simulando elementos da narrativa jornalística, as fake news vêm se proliferando em ritmo crescente, especialmente nos ciberterritórios (sites, blogs, redes sociais digitais, etc.), mas com efeitos deletérios em todos os âmbitos da vida atual. Agrava essa situação não apenas a emissão crescente, mas também a ampliação da aceitação e da recirculação desse tipo de narrativa.

O enfrentamento da perversão estruturada socialmente é algo complexo, tendo em vista que os perversos não se enxergam como sujeitos que erram ou que, porventura, devam corrigir rotas e comportamentos - as dissidências e/ou os desobedientes é que ousam sair da linha, sendo eles mesmos os culpados por tudo de ruim que lhes ocorre, sendo as "vítimas" consideradas as "culpadas" de seus mal-estares. Nesse âmbito, a lógica perversa é a de que direitos levam a desvios, a diversidade estimula aberrações, a liberdade enseja balbúrdia, a democracia produz corrupção, entre outros. Daí que também se pode perceber que, no discurso perverso, a receita do mundo é a visão do mundo do perverso.

Por fim, é preciso salientar que não necessariamente todos sejam perversos numa sociedade perversa, até porque há um intercâmbio de gerações. Dufour (2013, p. 280) esclarece, ao fazer a distinção da "cidade clássica" - composta por neuróticos que acreditam que existe um senhor ao qual precisam obedecer e ao qual devem a sua existência, da "cidade perversa" que:

\footnotetext{
O funcionamento pulsional será então privilegiado, em detrimento do funcionamento simbólico. Significa isso dizer que todos os habitantes dessa Cidade tornam-se perversos? Não, vimos que uma Cidade pode tornar-se perversa sem que os indivíduos que a compõem necessariamente sigam o mesmo caminho. Basta, com efeito, que a Cidade mobilize uma 'seleção natural' dos habitantes mais aptos a seguir esse caminho. A pressão sobre os demais indivíduos será então tão forte que, mesmo não perversos, eles serão obrigados a adotar comportamentos perversos. Essa observação leva a supor que na Cidade perversa podem existir (numerosos) neuróticos com comportamentos perversos (Dufour, 2013, p. 279).
}

Parece evidente o uso majoritário da perversidade sistêmica de hoje, formando "rebanhos egogregários" nos quais "o ego e suas satisfações pulsionais são valorizados por serem industrialmente explorados" (Dufour, 2013, p. 313), constituindo-se um tempo ímpar em violências, manipulações, preconceitos, intolerâncias, entre outros males tão exacerbados neste terceiro milênio, que não os inventou, mas que os potencializou com o esgarçamento dos pudores e o enfraquecimento da verdade factual como mediadora da existência. 


\section{CONSIDERAÇÕES FINAIS}

O enfrentamento desse cenário é por via da educação para a civilização, vista por Freud (1997, p. 57) como "a inteira soma das realizações e instituições que afastam nossa vida daquela de nossos antepassados animais, e que servem para dois fins: a proteção do homem contra a natureza e a regulamentação dos vínculos dos homens entre si". Além, é claro, do reforço das institucionalidades como meio de impor limitações aos planos e ação perversas, cujos objetivos se reduzem em si mesmos, basicamente ao gozo da dominação e da imposição de vontades egoísticas. As perversões dizem respeito a uma ordem de gozo a todo e qualquer custo. São mais afeitas à lógica do uso/descarte e menos à sistemática de durações e horizontes.

No entanto, vale ressaltar que, ao se falar em sociedade perversa, pode-se dar a impressão de que a sociedade neurótica era o paraíso e que temos hoje uma massa uniforme de sujeitos sem limite. Explicita-se que aqui se afirma o delineamento do "espírito do tempo" de nossa era, o que não implica homogeneizar estruturas subjetivas e intersubjetivas.

Há também que se destacar que, no contexto da experiência humana pela visão psicanalítica, nunca houve nem haverá um "paraíso sob o Sol”, tendo em vista as limitações básicas impostas aos viventes conscientes de sua condição frágil e atravessados pelo temor do desamparo estrutural, quais sejam, na visão de Freud (1997), habitar um corpo que envelhece, adoece e morre; habitar um planeta de condições ambientais imprevisíveis e por vezes mortíferas e coabitar o cotidiano com semelhantes hostis e agressivos.

Ou seja, cada tempo com seus desafios. Se o tempo da neurose produzia sujeitos e sociedades adoentadas pela disciplina, pela culpa, pelo remorso, entre outros elementos de uma existência sustentada pela devoção a um "pai redentor e tirânico", este tempo perverso alimenta uma era de mentiras, meias verdades, maldades, intolerâncias, individualismo, explorações, violências atomizadas, entre outros sintomas da queda do véu do pudor neurótico, escancarando uma cena grotesca que dialoga com o que há de mais "animalesco" em seres que apenas nascem aptos à humanidade.

A verdade factual como laço social é uma inestimável conquista civilizatória. A partir do saber científico como base para relações socioeconômicas e político-culturais, ela foi se tornando um norte potente à caminhada humana. Suplantando crendices, dogmas, discursos redentores (como os encontrados em nossa investigação) passou a empoderar cidadãos e comunidades, uma vez que oferta indistintamente referências mais objetivas e racionais para formulação de reflexões e decisões autônomas.

Por isso, a era da 'pós-verdade' é também a era do recrudescimento de regimes de violência e de ódio, numa guerra de narrativas personalistas e negacionistas, cujo alvo central é a visão racional do mundo e sua maior porta-voz, a verdade factual.

A verdade objetiva nunca foi unânime, mas o que se assiste no século XXI parece algo inédito. Parece urgente priorizar a restauração da verdade como laço fundamental de convivência. Revela-se imperioso repelir o culto à mentira e aos mentirosos, condenando-os como contrários do bem comum, especialmente em tempos de pandemia, quando a própria existência é ameaçada em termos planetários. 


\section{REFERÊNCIAS}

ARISTÓTELES, 2009. Política. Bauru, São Paulo: Edipro.

BARDIN, Laurence, 2009. Análise de conteúdo. São Paulo, Edições 70.

D’ANCONA, Matthew, 2018.Pós-Verdade. São Paulo: Faro Editorial.

DUFOUR, Dany-Robert, 2013. A cidade perversa. Rio de Janeiro: Civilização Brasileira.

FRAU-MEIGS, Divina, 2019. Faut-il avoir peur des fake news? La documentation française, Paris.

FREUD, Sigmund, 1997. O mal-estar na civilização. Rio de Janeiro: Imago.

FREUD, Sigmund, 2010.0 Mal-Estar na Civilização. São Paulo: Companhia das Letras.

HOUAISS, Antônio, 2006. Dicionário Houaiss da Língua Portuguesa. Rio de Janeiro: Objetiva.

KAKUTANI, Michiko, 2018.A Morte da Verdade. Rio de Janeiro: Intrínseca.

MANSOUR, Léda, 2019. The practice of online re-information. Revista Mídia e Cotidiano, $\quad \mathrm{V} \quad 13, \mathrm{n1}, 2019$. In:http://periodicos.uff.br/midiaecotidiano/article/view/27143Acesso em: 30 de maio de 2019.

LAPLANCHE, Jean \& PONTALIS, Jean-Bertrand, 2016.Vocabulário de Psicanálise. São Paulo: Martins Fontes.

MARTINUZZO, José Antonio, 2014. Os Públicos Justificam os Meios. São Paulo: Summus.

MATOS, José Claudio e RIPOLL, Leonardo, 2017. A zumbificação da informação: a desinformação e o caos informacional. Anais do XXVIII Congresso Brasileiro de Biblioteconomia. In: https://portal.febab.org.br/anais/article/view/1961, Fortaleza.

MOROZOV, Evgeny, 2018. Big Tech: a ascensão dos dados e a morte da política. São Paulo, Ubu Editora.

NEIVA, Eduardo, 2013.Dicionário Houaiss de Comunicação e Multimídia. São Paulo: Publifolha, 2013.

RIBEIRO, Renata Rezende, 2020. La réinfosphère brésilienne: fake news et intolérance dans I avie quotidienne numérique. Sociétés Reveu des Sciences Humaines et Sociales, n.147. Deboeck Supérieur.

SILVA, Andreia Fernandes. Porque é que as fake news se transformaram em protagonistas do jornalismo contemporâneo? Comunicação Pública, 2019, [s. I.], v. 14, n. 26.

SODRÉ, Muniz, 2002. Antropológica do Espelho. Petrópolis: Vozes.

TRAQUINA, Nelson (Org.), 1999. Jornalismo: questões, teorias e "estórias". Lisboa: Vega, 1999. 
ZELIZER, Barbie, 1992.Covering the Body: The Kennedy Assassination, the media and the shaping of collective memory. Chicago: Chicago University Press.

TANDOC, E. C.; LIM, Z. W.; LING, R. Defining "Fake News": A typology of scholarly definitions. Digital Journalism, v. 6, nº 2, p. 137-153, 2018. 